\title{
The impact of rurality on women's 'space for action' in domestic violence: Findings from a meta-synthesis
}

\author{
Kate Farhall \\ Centre for People, Organisation \& Work \\ RMIT University \\ AUSTRALIA \\ Bridget Harris \\ School of Justice \\ Queensland University of Technology \\ AUSTRALIA \\ Delanie Woodlock \\ School of Humanities, Arts \& Social Sciences \\ University of New England \\ AUSTRALIA \\ Contact author - Kate Farhall; katherine.farhall@,rmit.edu.au
}

\begin{abstract}
Men's violence against women is a global human rights issue, with domestic violence one of the most common forms (World Health Organization, 2017). The consequences of domestic violence include detrimental effects on victim-survivors' health, well-being, and sense of safety. To understand these impacts, the concept of 'space for action' seeks to evaluate how perpetrators of domestic violence narrow women's life choices, constraining their freedom (Kelly, 2003). In this article, we build upon the concept of 'space for action' by examining if, and how, rural geographical space and place can be used by perpetrators to constrict women's options for escape, or even shape the violence itself. In conducting a meta-synthesis of 32 global studies, we found similarities in rural women's experiences of violence. Perpetrators used both geographical space and rural social norms to constrain women's space for action. In particular, geographical and social isolation were used to hold women in literal captivity. Rural communities were often experienced as shaming and ostracizing. This provided women with few opportunities to help-seek and aided perpetrators in reducing women's spaces for safety. Women's space for action was also curtailed in the realms of finance, employment, and their ability to care for their children. These findings demonstrate that geographical place and space can be used by perpetrators to narrow and limit women's space for action. As such, rurality should be included in understanding how men's violence limits women's freedoms.
\end{abstract}

Keywords: domestic violence, rural, meta-synthesis, space for action, isolation, geography 
The impact of rurality on women's 'space for action' in domestic violence: Findings from a meta-synthesis - Farhall, Harris and Woodlock

\section{Introduction}

In recent years, a growing body of work has sought to examine the ways in which the geographical, social, and economic topography of rural communities contribute to unique experiences and challenges regarding domestic violence (e.g. Ragusa, 2017*; Wendt \& Hornosty, 2010*) ${ }^{1}$. Yet despite growing knowledge of the specificities of rural domestic violence, there is little understanding of how rural landscapes and communities may impact the space for action of women who experience domestic violence. 'Space for action' is a concept developed by Sharp-Jeffs, et al., in their 2017 article 'Long journeys toward freedom: The relationship between coercive control and space for action - measurement and emerging evidence' (building on Kelly, 2003). The 'space for action' model evaluates the ways in which the entrapment, surveillance, and restriction that are characteristic of coercive control significantly inhibit women's freedom by explicitly and implicitly curbing their behaviour (Sharp-Jeffs et al., 2017).

This is of particular importance in the wake of the global COVID-19 pandemic, where the primary mechanism to prevent transmission is to create space via physical distancing. For women subjected to domestic violence their space for action is effectively reduced to their household realm. This is not uncommon for victim-survivors, however emerging evidence has shown that perpetrators are capitalising on this enforced distancing to further curtail women's freedoms (Pfitzner et al., 2020). In particular, under the guise of protecting women (or themselves, and children) from COVID-19, perpetrators have increased their restriction on women's movements, monitored their use of phone and internet, as well as tracked their whereabouts using GPS in women's cars. There is yet limited evidence of how this is impacting women in rural communities.

In this article, we conduct a meta-synthesis of studies examining women's experiences of domestic violence in a rural context. In doing so, we evaluate the ways in which rural communities and landscapes have the potential to contract women's space for action. Initially, we begin by framing our research in the disciplines of feminist and rural criminology, feminist geography, and feminist understandings of violence against women. Then, we move to explain our research approach, detailing the process for arriving at a sample size of 32 articles and reports, and drawing on the guiding work of Saini and Shlonsky (2012) to ensure a rigorous analytical process. We also outline our coding scheme, designed to unpack the ways in which the rural space or place was either used by the perpetrator as part of their coercive control tactics, or in any other way contributed to a reduction in women's space for action, both during the relationship or post-separation. Following this, we turn to our analysis.

We approach our examination thematically. Firstly, we interrogate the interwoven themes of space, movement, and surveillance. Through this, we focus on the ways in which the rural space, as well as the spacelessness of technology in a rural setting (e.g. Harris \& Woodlock, 2019), can contribute to diminished space for action for women. Secondly, under a number of related subheadings, we move to examine how rural community life may constrict women's space for action. Rural community norms and forms of social organisation that can amplify feelings of shame and exacerbate community policing of women are foregrounded. Lastly, we explore the ways in which women's space for action in rural communities is curtailed in important areas of their lives and livelihoods - namely their financial standing and access to paid employment, as well as their ability to parent. 
Overall, we find that a meta-synthesis of women's experiences of domestic violence in rural contexts shows that rural space and place have specific impacts on women's space for action. Non-urban locations provide unique sets of social, economic, and geographical arrangements that can acutely limit women's options when subjected to domestic violence, as well as their ability to exit such relationships. Questions of distance and barriers to helpseeking combine with sets of gendered social relations to inhibit women's capacity to act freely or safely leave abusers. These are often compounded by complex or dependent financial arrangements, particularly where children are involved. If we are to provide effective supports to victim-survivors in rural contexts, knowing how rural lives, livelihoods, and landscapes obstruct women's space for action is key.

The focus of our review was male perpetrated violence against their female intimate partners. While our searches did not specify the sex of victim-survivors or perpetrators, all of those returned examined abuse in these contexts. Some studies included victim-survivors with diverse gender or sexuality identities, but overwhelmingly, victim-survivors were female and perpetrators male. While children, pets, and other family members or friends could be targeted, the abuse discussed was primarily intimate partner violence. We note that some scholars have critiqued the gender neutrality of such words such as 'domestic violence' and 'intimate partner violence' (in contrast to, 'woman abuse' or 'violence against women', for instance, see DeKeseredy et al., 2017). Though using an arguably more 'neutral' term, as discussed above, we have firmly grounded our review and analysis in a sexed and gendered framework.

\section{Space for action framework}

In order to further understand the experiences of women subjected to domestic violence in rural locations, we draw together several disciplines and areas of study. This includes rural and feminist criminology, feminist understandings of violence against women, and feminist geography. In particular, we build on Kelly's (2003) feminist concept of 'space for action', where Kelly argues that men's violence against women constrains women's choices, actions, and their 'life space' (building on Lundgren, 1998). Kelly argues that women's space for action decreases as they adapt their behaviour in attempts to avoid abuse, and this space is restricted and controlled by the perpetrators' regimes to limit her freedom. In an effort to measure how women's space for action increases after separation, Sharp-Jeffs et al. (2017) developed a 'space for action scale'. This scale focused on how women's lives were hindered by coercive control in domains including individual, social, economic, and community and tested if women's space for action expanded after separation from a violent perpetrator. They found there was a dramatic expansion of space for action after separation, which the researchers argue "demonstrates the difference that no longer living in an abusive gender regime makes for women" (Sharp-Jeffs et al., 2017, p. 20).

We draw upon this concept of space for action to understand how women's actions and sense of self are impacted by domestic violence and extend it to include the physical and geographical lived spaces that may be used to limit a woman's freedom. The geographical place and space where victim-survivors lives can be used by perpetrators as part of their coercive control tactics (Harris \& Woodlock, 2019). An understanding of domestic violence has been noted as being poorly covered in the field of geography (Pain, 2015). Early feminist geographers critically examined violence against women and the impact it had on women's access to public spaces (Valentine, 1989). Examining women's fear of men's violence in public spaces, feminist geographers contributed to understandings around how women's full 
The impact of rurality on women's 'space for action' in domestic violence: Findings from a meta-synthesis - Farhall, Harris and Woodlock

and free participation in society is limited and constrained. This fear of men's violence is conceptualised as a form of social control, with Valentine $(1989$, p. 4) labelling it as a "spatial expression of patriarchy".

This "spatial expression of patriarchy" has been examined by criminologists who focus on crime in rural locations. While feminist geographers have been mostly concerned about the impact of men's violence on women's freedom within public spaces, feminist and rural criminologists have looked at how location and space can shape women's private experiences of men's violence. Studies conducted internationally show that women in rural locations are made particularly vulnerable to domestic violence (Brownridge, 2009; DeKeseredy et al., 2017; DeKeseredy \& Schwartz, 2009). In relation to this vulnerability, Sandberg (2013) argues that rurality should be included in our understandings of the intersectional nature of violence against women. However, rurality is not a form of intersecting oppression such as race and class, but instead, the rural location poses "particular kinds of vulnerability to individuals" (p. 361). These particular kinds of vulnerability include higher levels of intimate partner stalking (Logan et al., 2007), threats with and use of weapons (Logan et al., 2003), torture (Websdale \& Johnson, 1998) and domestic homicides (Gallup-Black, 2005) in rural areas as compared to urban environments.

Our aim in this meta-synthesis is to draw these theories together and extend them to further understandings of how perpetrators can capitalise on the vulnerabilities that rurality imposes on women and use the rural location to narrow and constrain women's space for action.

\section{Methodology}

A qualitative meta-synthesis was used to collect, organise, and interpret the data. Qualitative meta-synthesis studies go beyond the collation and comparison of large swathes of data, as in quantitative meta-syntheses, to "produce a deeper understanding of a particular issue" (Noble-Carr et al., 2019, p. 182). In this way, qualitative meta-syntheses can generate the development of new theoretical insights, while on a practical level, their findings can also be used as an evidence base for policy and practice (Veltri et al., 2014). Findings from a large number of studies are reframed through the meta-synthesis to create a new understanding of an event or phenomenon (Sandelowski \& Barroso, 2007).

The systematic review involved two screening processes. In the first process, searches were conducted in the most relevant academic databases we could access: EBSCO, CINAHL, Medline, and Scopus. Searching in Google Scholar and Google ensured both scholarly and grey literature was captured. All results in database searches were included. Search results from Google Scholar and Google were reviewed and included until sources retrieved were deemed no longer relevant or to reflect the systematic review focus. Two team members conducted the searches to ensure the same articles were captured, using the terms: 'rural OR regional OR remote OR non-urban' AND 'semi-structured interviews' OR 'focus groups' OR 'in-depth interviews' AND ‘domestic violence' OR 'domestic abuse' OR 'intimate partner violence' OR 'family violence' OR 'dating abuse'. This range of terms ensured that identified articles included i) non-urban related research; ii) qualitative studies (with a focus on interviews and focus groups); and iii) the different conceptualisations of domestic abuse. A twenty year age range, from 1999-2019, ensured the most recent scholarship was canvassed. 
A total of 170 documents passed the first screening criteria. There were some records returned - articles and university theses - which were excluded due to access issues. We reviewed the material, reflected on the results, and established criteria to conduct the second screening process. We determined this was to be studies containing: i) a minimum data set of ten rural victim-survivor participants; ii) featuring women's voices through quotes; iii) a focus on domestic violence (as opposed to abuse being a sideline or smaller part of a study) so information about barriers that women faced could be ascertained; iv) and rural participants, so that the ways that location shaped the impact of violence could be investigated. Rurality was not awarded a demographic or geographic definition, as we recognised there is no universal definition for rurality internationally (or, indeed, within nations). Studies focused specifically on regional as opposed to rural areas were excluded. In the second screening, 32 articles and reports passed screening, based on 30 distinct research projects.

Of the 30 studies detailed across the 32 articles and reports, the majority $(\mathrm{N}=26)$ utilised interviews; a smaller number utilised focus groups $(\mathrm{N}=4)$. The total number of victimsurvivors featured in all studies was 888 . Several texts included in the study were completed by authors of this article. To ensure neutrality of coding, those articles were not coded by the same author. Of the studies presented in the articles reviewed, in detail, by our team, half centred on the Global North ( $\mathrm{N}=10$ from the United States of America, $\mathrm{N}=3$ from Canada, $\mathrm{N}=1$ from England, $\mathrm{N}=1$ from Ireland) and half on the Global South $(\mathrm{N}=10$ from Australia, $\mathrm{N}=1$ from Bangladesh, $\mathrm{N}=1$ from India, $\mathrm{N}=1$ from New Zealand, $\mathrm{N}=1$ from Malawi, $\mathrm{N}=1$ from South Africa). The division included here is geographical and we note that such southern criminological frameworks have a division (especially the situation of Australia in the symbolic Global South) has been critiqued (Moosavi, 2019). We also advocate for scholars to engage further with studies conducted in the geographical and symbolic Global South (see Carrington et al., 2019) in future reviews, including through translation processes and alternative search processes. While some strategies - for instance, translation programswere utilised in our searches, these did not yield any further results in languages other than English. We acknowledge that there is likely further literature in other dialects that this review has not included (both from the Global North and South).

An important step in conducting a qualitative meta-synthesis is to conduct a quality assessment of the data set. After the second screening was complete, we conducted a quality assessment of the 32 remaining articles. This process was modelled on Saini and Shlonsky's (2012) 'Qualitative Research Quality Checklist', and involved assessing factors such as each article's framework, ethical rigour, immersion in the data or community, sampling, methodological reliability, data audit trail, and analytical approach. As per the requirements of a qualitative meta-synthesis, no articles were excluded as a result of the quality appraisal (Saini \& Shlonsky, 2012). Studies included in the meta-synthesis were generally of high quality, included rigorous data collection and analysis methods, and reported ethical practices.

After the quality assessment process, we came together to develop a coding scheme to analyse the impact of rural space and place on women's space for action. Thematic categories were developed through both a deductive and inductive process. As all three team members had immersed ourselves in the data throughout the screening process, all were familiar with the data prior to coding. This, combined with our previous work in the area of rural domestic violence, informed the eleven coding categories we developed. These categories centred on aspects of rural place and space that could either be directly employed by the perpetrator as a 
The impact of rurality on women's 'space for action' in domestic violence: Findings from a meta-synthesis - Farhall, Harris and Woodlock

tool of coercive control or otherwise serve to contract women's space for action. Categories included geographical concerns around isolation and movement; practical problems, such as barriers to help-seeking; as well as emotional challenges, such as shame and fear, as they relate specifically to rurality. Codes were applied by all three researchers in line with the principles of thematic analysis (Braun \& Clarke, 2006) and drawing on previous qualitative meta-syntheses (Noble-Carr et al., 2019; Jovanovski \& Cook, 2019).

In communicating our findings below, we follow Noble-Carr and her colleagues (2019) in their desire to give voice to the experiences of the participants in the studies they analysed. They point to the fact that "the use of original participant data is recognized as an important strategy to enhance the credibility of meta-synthesis reporting", and that they, therefore, choose to employ direct quotes from participants to support the primary themes identified (Noble-Carr et al., 2019, p. 184). We also chose to foreground women's voices in our presentation of the data. As such, while findings, including our interpretations, inform our analysis below, we have only used participants' direct quotes to evidence our arguments. In doing so, we ensure that our analysis reflects the experiences of rural victim-survivors.

\section{Findings}

This section describes the common themes found throughout the studies in relation to how rurality impacted and interplayed with women's experiences of domestic violence and their space for action. Throughout the literature, women described how both the geographical place and the rural space shaped the abuse they were subjected to, including the types of abuse, the barriers they faced seeking support and help, and when leaving the perpetrator. While there was a large amount of consistency across the studies, we also found that some studies did not use a rural lens when analysing the abuse women were subjected to, potentially missing the significant ways that rurality impacted women's experiences. The main themes observed included abuse tactics such as isolation (social and geographical), surveillance (including the use of technology), control of movement, and causing fear (including through the use of threats to harm and kill and use of weapons).

Across the studies, women encountered challenges and complications when seeking help for the abuse because of shame and a lack of privacy, which was exacerbated by living in a small community. Also noted across the literature were networks of abuser allies and/or peer support networks that could facilitate, minimise or legitimise violence. These and other social structures (such as religious or cultural structures) could function to exclude or attempt to discredit women or hinder their opportunities to respond to violence. A lack of knowledge and confidence in legal and justice systems and little access to these or other services compounded and complicated women's engagement with these channels. Throughout the various works, demographic and ideological features were said to shape and compound these barriers. Women - and, their abusers - were more likely to be known to those in their legal, justice, health, and support agencies. Public disclosure and attempts to seek information and assistance were widely reported to be confronting for victim-survivors. Overall and conclusively, the literature indicates that women's space for action must be examined and understood in regard to rurality.

\section{Isolation, control of movement and surveillance}

While rural communities are often mythologised as close-knit, isolation-both geographical and social—was a key abuse tactic used by perpetrators to limit their victim- 
survivors' space for action (Bosch \& Bergen, 2006*; Burton et al., 2016*; Doherty \& Hornosty, 2008*; George \& Harris, 2014*; Loxton et al., 2003*; Mackenzie \& Mackay, 2019*; Martz \& Saraurer, 2000*; National Rural Crime Network, 2019*; Neilson \& Renou, 2015; Wendt 2009*; Wendt et al., 2017*). Across the studies, there was mostly consistency in how isolation impacted women and children. The National Rural Crime Network's (2019*) investigation of domestic violence in rural England summarised the two main ways that perpetrators enforced isolation; through physical and or geographical means, such as deliberately moving to a remote area to live; and through mental and or social isolation, such as separating the woman from friends and family, as well as capitalising on tight-knit rural communities by limiting her opportunities to build relationships, therefore reinforcing his control and her isolation from the wider community.

A participant in the National Rural Crime Network's $\left(2019^{*}\right.$, p. 28) study detailed the ways in which these forms of isolation dovetailed to limit her space for action. She explained:

I had no contact with any services, home-schooled the children ... We had an elderly neighbour and a holiday home close by but that was it. No doctor, no post office, no support services, nothing ... His behaviour got worse and because we worked from home and he didn't drive I did everything ... I was a mile away from the nearest person.

Similarly, a woman in Bosch and Bergen's $\left(2006^{*}\right)$ research linked the way that physical and social isolation closed down her options for seeking help. In particular, her ex-husband's employment as a minister in a small community meant decreased avenues for social support:

I sometimes had access to long distance telephone and only rarely had access to a car. Sometimes we lived 26 miles from town. Sometimes we lived in small towns. In such small towns there is no privacy. I lived in a glass house. I was always told to keep my mouth shut because of his occupation. I had no one to talk to. (p. 315)

In this way, we can see how geographical and social isolation were often intertwined in perpetrators' attempts to close down women's space for action; a situation that was at times compounded by rural social norms and community structures.

Throughout the literature, women explained that perpetrators would often move to isolated areas as a tactic of control. For example, one woman said:

Unexpectedly he announced one day that he had bought a house on an island off the south coast and we were to move there. As soon as I saw that house I thought that's the place I am going to die. (National Rural Crime Network, 2019*, p. 29)

This intentional isolation of victim-survivors not only narrows women's space for action within the relationship but also limits her escape options (see also Murray et al., 2019*). In this sense, physical isolation can be the perpetrator's most effective tactic, as it can result in the victim-survivor being "literally captive" (National Rural Crime Network, 2019*, p. 8).

In contrast to the other scholarship reviewed, Wendt et al. $\left(2017^{*}\right)$ found the majority of women in their research did not feel isolated due to their geographical location. Instead, women generally expressed that distance was not a barrier and services could still be accessed. However, women living more remotely (for example, over an hour from a town) 
The impact of rurality on women's 'space for action' in domestic violence: Findings from a meta-synthesis - Farhall, Harris and Woodlock

did feel that physical distance was a factor in their ability to access services and that perpetrators used distance as a form of control. A participant noted:

I was completely dependent on him, even for petrol. He would drain petrol from the car. We lived out of town and there was nobody next door. The isolation is daunting in terms of planning. There was nothing or anyone to help me really. (p. 36)

As such, it may be that the extent to which women are physically isolated impacts on an abuser's ability to constrain her space for action.

The main form of isolation that impacted women in the study by Wendt et al. (2017*) was social. This shaped the ways they coped with domestic violence, as well as their options for help-seeking. Women felt that, as with geographical isolation, perpetrators deliberately isolated them socially. While this tactic is not unique to abuse in rural locations, coupled with physical isolation, it resulted in women feeling they had no avenues for support. A participant from the study by Doherty and Hornosty $\left(2008^{*}\right)$ said:

And, then you're in a rural situation where you're with all of their family, none of yours. They take your vehicle, they threaten you ... [I'm] balling my head off, thinking, 'I cannot believe I am in this situation', scared to death to leave, because it was all his family. (p. 75)

Geographical distance could therefore compound social isolation for victim-survivors, leaving them feeling trapped. Close-knit communities could also work to reduce women's space for action through rendering them 'hemmed in'; in this example, by the abuser's family.

Related to this tactic of isolation was the control of women's movement. In rural areas this could be achieved relatively easily, through limiting women's transport options. Across the studies women spoke of having their cars sold, petrol siphoned from their cars, and restricted access to public transport (Loxton et al., 2003*; Pitt et al., 2019*). One woman from the study by Loxton et al. $\left(2003^{*}\right)$ told researchers her ex-partner sold her car, and she had to ask permission to use his vehicle, which was rarely given. Another participant was not allowed to get her licence; when she finally did get permission, she was not able to use the perpetrator's car. He also controlled her access to money, meaning she could not catch public transport. Michelle, in Pitt et al.'s (2019*) study, summarised the impact of this on women in rural communities:

People don't realise that there's so many people stuck out in the middle of nowhere ... and you've never been allowed to talk to anyone - how are you meant to think in your head what to do. (p. 37)

This reality of being "stuck out in the middle of nowhere" evocatively describes how women's space for action is literally, and figuratively, closed down through the perpetrator's tactics to isolate her and control her movements. She is geographically stuck, unable to move within the physical space, and she is mentally stuck, unable to envision what steps she needs to take towards freedom. Isolation and control over women's movements by the perpetrator leave women with little option but to try to just survive each day, feeling that there is no longer-term solution that they can access (National Rural Crime Network, 2019*). 
Women's space for action was curtailed by perpetrators in what has been defined as a 'spaceless' location; the use of technology (Harris \& Woodlock, 2019). Technology was one potential way that victim-survivors might bridge the distance between themselves and safety, yet this avenue for action was shut down for many women. Closely linked to the tactic of isolation, as well as surveillance of women's actions and movements, was perpetrators' monitoring and control of victim-survivors' use of technology. Multiple studies detailed how perpetrators focused on limiting and controlling women's use of their phones (Bosch \& Bergen, 2006*; National Rural Crime Network, 2019*; Wendt \& Hornosty, 2010*). For several women, their landline phone was their only connection with their friends and family:

I had two or three friends in the next village but no way I could reach them without walking there. We lived in the valley and had a really non-existent mobile signal and my partner removed the telephone from the house because he said I didn't need it. (National Rural Crime Network, 2019*, p. 29)

This control of communications technology by abusers was a common way in which the space for action of victim-survivors in the study was limited.

Women mentioned perpetrators removing telephone cords, buying them new phones for them and deleting all the address book contacts in previous phones, listening to calls whenever they would talk with family and friends, and keeping track of their phone bills. A perpetrator in the study by the National Rural Crime Network $\left(2019^{*}\right.$, p. 31) gave a 'gift' of a new phone to the participant, but it was in reality another way to further isolate her. She said:

Once I came in and he had wrapped up a new phone for me which he handed over ... When I opened it up it had all been set up for me but all the pictures from my old phone and my friend's numbers weren't on there ... When I asked for my old phone to transfer them over he said he had destroyed it because everything I needed was on the new phone ... I was massively upset because it was like he had removed my former life - just wiped it clean.

While considered spaceless, a perpetrator's control of technology effectively narrowed women's space for action, further separating them from family and friends, and their past.

As asserted in the National Rural Crime Network (2019*) report, geographical isolation of women in rural locations, can literally result in perpetrators holding their victim-survivors captive. However, across the literature, women's stories show that isolation can also be a result of perpetrators controlling women's opportunities for social connections, control of their movements, and using technological surveillance. These forms of abuse can leave victim-survivors with a narrowing of their space for action, both their physical space for action, and their mental space for action. Herman (1997, p. 74) writes that "domestic captivity" is often unrecognised by wider society, but that "home may be a prison for women and children". This prison that Herman (1997) details rarely has physical bars, and barriers are often invisible, yet prolonged captivity with the perpetrator results in women and children surviving by living by the rules enforced by him. In rural locations, this is heightened by the isolation that geographical distance can provide the perpetrator. Women and children are trapped in every sense of the word, and the perpetrator can exert his control with relatively little interference. As Michelle (in Pitt et al., 2019*) explained, she felt so captive she could not even think in her head what to do. Herman (1997, p. 91) describes how prolonged captivity can result in victim-survivors' "safe sphere of initiative" becoming eroded, where 
The impact of rurality on women's 'space for action' in domestic violence: Findings from a meta-synthesis - Farhall, Harris and Woodlock

any action taken is perceived to have "dire circumstances". However, it is important to highlight that participants across the research studies were able to speak out because most had found a way to escape the captivity of the perpetrator.

We unpack social isolation further below, as it pertains to community structures and ties. Specifically, we explore the ways in which social isolation was produced through women's feelings of shame, of ostracism by their abuser, or via abuser allies or peer support networks that bolster or turn a blind eye to perpetrators' actions. Exclusion or disconnection could also be motivated by or attributed to social structures (shaped by various factors such as rural gender structures, cultural values, religion) that facilitated, legitimated or minimised abuse (see Burton et al., 2016*; George \& Harris, 2014*; Loxton et al., 2003*; Mackenzie \& Mackay, 2019*; Martz \& Saraurer, 2000*; National Rural Crime Network, 2019*; Neilson \& Renou, 2015*; Wendt, 2009*; Wendt et al., 2017*). Culturally and linguistically diverse victim-survivors from minority groups residing in predominantly white rural areas also expressed a feeling of social isolation (Murray et al., 2019*).

\section{Privacy and shame}

Features of rural areas - population density and 'being known' - shaped abuser ally/peer support networks and (could be a deterrent to) help-seeking and effectively narrow women's space for action (Bosch \& Bergen 2006*, p. 315). Abusers used these networks to maintain control and enact harm, post-separation. In DeKeseredy and Hall-Sanchez's (2017*, p. 840) study, the offender told a woman he had widely distributed a videotape of a sexual assault throughout their community. After she sought assistance from police, an officer she consulted told his wife about the tape and "because this town is a small community and everybody knows everybody", this information was easily shared with her social network. Here, the deliberate actions of the perpetrator constrained the already narrow space for action that the victim-survivor had in a small community, through publicly shaming her.

Intel about police contact was also garnered through technology. Women in Lichtenstein and Johnson's study (2009*, p. 298) described how police scanners facilitated "nosiness". Consequently, women might elect not to seek assistance. As one participant explained:

[w] hen you call police sometimes the [neighbors] have scanners and before they even get over here the thing is all over the community. So a lot of times we don't call the sherrif's department because everything you are trying to report for your benefit, they [neighbors] know it before they cross the bridge.

Even without technology, as young participants in Mackenzie and Mackay's (2019*) study discussed, "the fact that you're country people ... gossip spreads like wildfire". Thus, "there's kind of a fear that you're going to be talked about or if you say something you're gonna get misconstrued and passed along" (p. 27-28, see also Neilson \& Renou, 2015*). In this vein, older African American women in Lichtenstein and Johnson's (2009*, p. 295) study identified that ministers and deacons would not keep disclosures confidential;

'We don't trust him enough to talk to him about things like that' (Bertha) 'The day you talk to him he will talk to someone else and there it go' (Araminta) 'All your business will be out on the street because the minister will let it out in the congregation' (Gertrude) 
'...before he leave church, he'll call the [male] deacons... He gonna take his deacons back there and they gonna discuss you. So if you got a person to talk to, talk to them, but don't make it you minister' (Helena)

In this way, the 'everyone-knows-everyone' character of rural communities could further impact women's space for action, by causing them to self-police to avoid community scrutiny.

In such contexts or where victim-survivors or their abusers were well-known, anonymity, privacy, and confidentiality when disclosing violence or accessing support (from friends, support workers, police, court workers or medical professionals) were tenuous at best (Bosch \& Bergen, 2006*; George \& Harris, 2014*; Lichtenstein \& Johnson, 2009*; Loxton et al., 2003*; Neilson \& Renou, 2015*; Ragusa, 2013*). This was especially true for women from certain cultural contexts, such as Bangladesh, where family 'honour' is highly prized (Khan, 2015*) or where women occupied leadership roles in their community. In George and Harris's (2014*, p. 50) study Keri, a well-known member of her Aboriginal and Torres Strait Islander community, spoke of her fears that "everyone would know" about the abuse and not "want[ing] to be a failure to the world". These feelings of shame, and not wanting to "be a failure" can further limit the already small network of support in rural locations for women subjected to domestic violence, constricting her space for action and narrowing her helpseeking pathways.

\section{Social structures facilitating abuse}

Some works documented the ways that particular community and belief structures could foster and facilitate violence and abuser allies. A woman in Hornosty and Doherty's (2002*, p. 24) research shared that: "[i]n the country, religious values are pretty strong. Growing up, everyone told me that is a wife's duty to take care of her husband and children and make the marriage work - no matter what". Responsibility and blame for experiencing abuse were also recorded by Lichtenstein and Johnson (2009*), who investigated the role of religion in older African American women's narratives of violence. Felicia lamented that:

If you are church-minded people think of you as being outstanding in your community and they look up to you. [Domestic violence] is what kills people's trust in you right there. The first thing they say is, 'I thought she was nice. She goes to church, she reads her bible and all of that, and she let that happen to her'. (p. 295)

Perpetrators held in high esteem in religious communities were, in some works, offered support, such as the abuser who was a minister in Bosch and Bergen's (2006) study, noted above. As explored further in this article (see 'privacy' discussion), throughout the literature, confidentiality was also not assured in contact with church officials.

Women in Khan's (2015) research highlighted how cultural values could lead to an emphasis, from women's families, to maintain marital relationships above all else, even if the perpetrator was abusive, or risk shunning. After disclosing violence, Tanni's "parents said husband is everything for a Bengali woman and making marriage work is your responsibility" (p. 257). Pallabi's mother told her "never go out of your husband's home, if he batters you, accept it - even if he kills you, you will go to heaven" (p. 257). The absence of bystander assistance was present in other accounts. Nova's parents emphasised they could not assist her; they "suggested I should bear it silently since it was not possible for them to 
The impact of rurality on women's 'space for action' in domestic violence: Findings from a meta-synthesis - Farhall, Harris and Woodlock

shoulder my burden. They also advised me not to disclose things to our relatives" (p. 260). These accounts were not rural-specific but drawn exclusively from rural women. They speak to a need to consider intersectionality in collecting and analysing rural data and consider how other factors may limit a woman's space for action.

\section{Abuser allies and peer support networks}

Overall, the literature documented ways that geographical, social, and ideological features of communities functioned (often in concert) to foster, facilitate and legitimise violence against women, as well as further limit women's space for action. Using a range of terms, various articles referred to traditional or conservative gender norms and constructs of gender in rural places as reinforcing or justifying violence. One woman in Loxton et al.'s $(2003 *$, p. 7) research who had been shot by her abuser, post-separation, spoke of being ostracised in the workplace after exiting a violent relationship, which she felt was "because I was the female ummm I was being told that I was the bad person you know... The man always seems to be right". Women seeking assistance or ending a relationship reported being demonised and accused of 'breaking up' a family (George \& Harris 2014*; Neilson \& Renou $2015^{*}$ ). In small, close-knit communities, the insider/outsider dichotomy and how this could serve to isolate victim-survivors was acknowledged; "if you're not there in with them, you're basically pushed out into the gutter" (Wendt et al., 2017*, p. 33, see also National Rural Crime Network, 2019*). Additionally, in Neilson and Renou's $\left(2015^{*}\right.$, p. 83) project, Sian spoke of her community siding with her ex; "“Oh poor, poor thing, look what you've done' [to him the offender]".

Scholars and advocates documented cases of third parties maintaining that the offender was a 'lovely', 'charming', 'nice' person, a 'good guy/bloke' [a colloquial Australian term] not capable of enacting harm (George \& Harris, 2014*; Neilson \& Renou, 2015*). Also present was what DeKeseredy (1990) has conceptualised as 'male peer support theory'; whereby abusive men forge networks of patriarchal and abusive peers. In this climate, victimsurvivors suggested that violence "happens a lot... [and] it's not until you walk away from that, that you realise it's not a normal way to be" (Neilson \& Renou, 2015*, p. 89). Shared beliefs and values can reinforce attitudes associated with, and that underscore violence against women, thereby providing resources and legitimacy for violent activity (DeKeseredy, 1990). The presence of such structures and practices was widely documented, although not typically using the aforementioned terms 'abuser allies' or 'peer support networks'. Engagement in a sports club, for instance, forged strong networks and alliances for abusers (George \& Harris, 2014*; National Rural Crime Network, 2019*; Neilson \& Renou, 2015*). Abuser allies/peer support networks were also visible in formal interactions. When disclosing violence to police, for example, women were often told they were "making it [her disclosure of violence] up and that he was a good guy who wouldn't do that" (George \& Harris, 2014*, p. 159).

The reluctance of informal support networks to intervene was observed in multiple works (Khan, 2015*; National Rural Crime Network, 2019*; Neilson \& Renou, 2015*). This was especially true when abusers were seen as respectable, powerful, and well-known figures, such as business owners (Martz \& Saraurer, 2000*; National Rural Crime Network, 2019*; Wendt, 2009*). Numerous articles referred to what we have classified as 'abuser allies' (see Bancroft, 2002), where others in a social network offer support for the abuser or their narrative. Consequently, some women found that friends, family, and police would deny, minimise, trivialise or seek to discredit allegations of violence (George \& Harris, 
2014*; Hornosty \& Doherty, 2002*; Mackenzie \& Mackay, 2019*; Martz \& Saraurer, 2000*; National Rural Crime Network, 2019*; Neilson \& Renou, 2015*; Ragusa, 2013*; Wendt et al., 2017*). A victim-survivor in Hornosty and Doherty's $\left(2002^{*}\right.$, p. 20) research emphasised that her friends "don't talk about it [abuse]. They just brush it [an abusive experience] away - all women go through that... my friends don't believe in it [abuse]". In some cases, friends actively aligned with abusers. Multiple participants in Mackenzie and Mackay's (2019*) cohort (of young Australian rural women) reported that friends had told abusers of their plans to end the relationship. Additionally, the authors found reports of those in abuser's social groups actively hiding abuse: "I tried to go to the police about it", Jasmine recounted, "but he denied everything and his best mates stuck up for him and said he'd never do that so it completely backfired for me, cos no one believed me" (p. 27). In Khan's (2015*, p. 264) cohort from Bangladesh, Sharifa shared that her ex has "influenced my witnesses", in court cases; "some of them promised to go [to testify on her behalf], but finally did not".

Women in George and Harris's (2014*) study reported police seemed to minimise, excuse, or deny abusers' actions, especially where the abuser was a friend or held in high regard. A text from Rohini's ex said, "'I know the police officer, he knows your family and he thinks you're a joke and this whole case is a joke"' (p. 161). Likewise, Robyn, in Neilson and Renou's $\left(2015^{*}\right.$, p. 57) examination, recalled police would "ring him [her abuser] at the fire brigade at work and it was a joke honestly". She felt "they sort of seemed to be in each other's pockets". Some offenders expended energy building these relationships and influence. A participant in Ragusa's (2013*, p. 704) project contacted police 27 times but felt officers "didn't take things seriously" and "didn't do anything about it". She claimed her abuser "worked on the police, he's got the police eating out of this hand" and "even sent the Commander Chief a letter of how professional and great the police were". Women in the National Rural Crime Network $\left(2019^{*}\right.$, p. 38) study worried police would "take this point of view anyway-you just get treated like shit. I don't trust the police to do anything for people like me". In one study, a woman identified a serving police officer as her abuser (Ragusa, $2013 *)$.

In some studies, community members seem to actually engage in abuse or stalking. Various literature recorded that informal surveillance of a woman was performed by an abuser's friends or family, which women felt limited their freedoms and opportunities to help-seek;

he's so popular... that's why I don't want to go out very often because I always see one of his friends and they are always chatting to me and I don't want them to know where I am. Yeah what worries me is one day if I'm walking around and one of them will see me, they'll follow me. (Murray et al., 2019*, p. 101)

Likewise, abuser allies seem to assist surveillance of victim-survivors in Bosch and Bergen's $\left(2006^{*}\right)$ examination, though whether or not they were commissioned to do so was unclear. One woman spoke of her ex who had issued threats to kill if she even engaged with those in her social network. She recalled that "[i]f I even talked to anyone, it seemed to get back to my husband and he didn't like me talking to people in the community" (p. 317). These social networks served to limit the space that women had for taking action and constrained the already small opportunities she had to leave the perpetrator. 
The impact of rurality on women's 'space for action' in domestic violence: Findings from a meta-synthesis - Farhall, Harris and Woodlock

\section{Limited services and alternative accommodation}

Limitations related to alternative accommodation, support and medical services, agency access, and general under-resourcing, were noted in various reviews (George \& Harris, 2014*; Hornosty \& Doherty, 2002*; Khan, 2015*; Mackenzie \& Mackay, 2019*; Martz \& Saraurer, 2000*; National Rural Crime Network, 2019*; Neilson \& Renou, 2015*). Closures of organisations in rural areas - as a result of funding or resources cuts - further complicated help-seeking, as a woman consulted by Hornosty and Doherty $(2002$, p. 16) noted: "[w]e used to have a health centre, but it closed. All the services are in [urban area] so you don't bother getting help". In addition to services being restricted geographically, some literature documented an ideological difference as restricting usability of services. A woman in Hornosty and Doherty's (2002*) research described how:

$[\mathrm{u}]$ sing services, like the transition house, is difficult not only because it is far away, but they don't really understand farm women. The staff are kind and sympathetic, but they don't seem to know what it means to come from a rural home. You almost feel ashamed for placing so much value on it. (p. 25)

If women cannot access support services and alternative accommodation, or appropriate versions of these, their space for action becomes limited to their informal supports and their own ability to endure or escape the abuser, unaided.

Similarly, victim-survivors in Martz and Saraurer's (2000*, p. 28) project cautioned that it was problematic to utilise refuges in urban areas, because " $t]$ his person already lost the roof over their head and the floor under their feet", and relocating removed supports and "most people in these small towns have lived here for ever and they grew up here and... their families are here and you can't be hauling them 200 miles away". Moving to another area was identified as challenging for women, their children, and finances. Subsequently, women might hesitate to end relationships (see Martz \& Schwartz, 2000; Wendt, 2009*). Thus the absence of alternative accommodation, in not being suitably close or geared to rural regions, restricted women's options and space for action when exiting violence. There was literally no space for them to go. There were internal challenges too, such as emotional attachments to land, family, or businesses (e.g. farm or winery) (Wendt \& Hornosty, 2010*).

\section{Knowledge and confidence in formal responses}

Shame was frequently said to be a consequence of the absence of privacy in rural areas (Bosch \& Bergen, 2006; Loxton et al., 2003*; Ragusa, 2013*). Being known to police, court staff, lawyers or support workers, and the deficit of private spaces in various agencies resulted in no or little confidentiality (George \& Harris, 2014*; Neilson \& Renou, 2015*). A victim-survivor in George and Harris's 2014* (p. 230) study explained, "[t]he public thing in court is too hard because you feel ashamed. You keep it hidden for years and then going from that to public is hard", which could result in women minimising or downplaying violence, "because there's people behind you listening" (see also Ragusa, 2013*). Similarly, Neilson and Renou's $\left(2015^{*}\right.$, p. 70) participants spoke of anxieties and "degrading" experiences; "expos[ing] all your privacy to complete random strangers" in the courtroom, in "a small town" when "people peek in when they are driving past".

Limited knowledge of legal, police or court processes (Khan, 2015*; Neilson \& Renou, $2015^{*}$; Ragusa, 2013*) or concerns with policy and practice (such as co-arresting, see 
Lichtenstein \& Johnson, 2009*) or the effectiveness or structure of the justice system (National Rural Crime Network, 2019*; Neilson \& Renou, 2015*; Ragusa, 2013*) were identified as barriers to engaging formal responses. Rural and religious values, prioritisation of family units, and vocal opposition to police responses also deterred women from seeking help from these channels (Hornosty \& Doherty, 2002*; Loxton et al., 2003*; Mackenzie \& Mackay, 2019*). The capacity of police to provide culturally specific supports-including interpreters - hindered some women's ability to contact and communicate with officers (Murray et al., 2019*). Victim-survivors also identified frustrations and inadequacies when 'outside' (urban) representatives (e.g. judges), unfamiliar with rural life were brought in, delivering impractical or problematic rulings for the jurisdiction (Pitt et al., 2019*).

\section{Threats and fear}

In efforts to extend isolation and control and, evoke fear, abusers made threats and attempts to harm women, others (friends, family, neighbours), pets/livestock or themselves (Bosch \& Bergen, 2006; Doherty \& Hornosty, 2008*; George \& Harris, 2014*; Hornosty \& Doherty, 2002*; Khan, 2015*; Loxton et al., 2003*; Pitt et al., 2019*; Wendt et al., 2017*). Abusers, in some reports, made such threats if women even engaged with their social networks. For example, a victim-survivor in Bosch and Bergen 2006's (p. 317) research reported that her partner "threatened to kill me if I talked to anyone". Victim-survivors (in various works) have expressed fear that people in their abuser's social network might be commissioned or elect to engage in surveillance which elevated the threat of fatal violence (Harris \& Woodlock, 2019). Sometimes animals were killed during relationships (Doherty \& Hornosty, 2008*). Assaults or attempted homicide (see Khan 2015*; Loxton et al., 2003*) appeared to happen most commonly, post-separation, in line with what has been observed in the literature more broadly (see DeKeseredy et al., 2017). Geographically isolated women in Hornosty and Doherty's $\left(2002^{*}\right.$, p. 1) work who were subjected to threats of homicide worried their bodies would not be discovered; "who would know-the farm is so isolated". In addition to feeling fearful in relationships and during attempts to exit relationships, women described fear with disclosing violence, including to police or courts. Women mentioned being "too scared to go court" and feeling "[a]bsolutely ill with fear" when attending court for matters pertaining to violence, especially when they had to wait or pass through areas where their abuser was waiting, often without security (Neilson \& Renou, 2015*, p. 45, 69). Ultimately fear could function to hold women captive, whether wielded by the abuser, or as a result of concerns regarding the ability of justice systems to secure their safety and further limit her space for action.

\section{Finance, work and mothering}

The data pointed to several ways in which rural economic and social contexts might stifle space for action in the areas of finance and employment. The way in which community values impact decisions around work, with financial flow-on effects, is demonstrated by a woman in Maselesele and colleagues' study $\left(2009^{*}\right.$, p. 2535), who puts it simply: "my husband is a breadwinner, what will happen to me and my kids if I leave him?". Traditional values around women's household role, as touched on in previous sections - which tend to be more potent in rural areas - can reduce space for action by limiting women's financial independence, constraining their social world through identifying the home as their principal realm, as well as psychologically foreclosing on space for action by identifying separation as an unacceptable course of action (e.g. George \& Harris*, 2014; Hornosty \& Doherty, 2002*; Khan, 2015*; Lichtenstein \& Johnson, 2009*; Maselesele et al., 2009*; Pitt et al., 2019*; 
The impact of rurality on women's 'space for action' in domestic violence: Findings from a meta-synthesis - Farhall, Harris and Woodlock

Ragusa, 2013*). These community norms can economically and socially bind women to relationships through defining their roles as wives, mothers, and homemakers.

Those community norms that delegate men as breadwinners and women as homemakers, and in the process restrict women's space for action, are deeply rooted in notions of hegemonic masculinity and patriarchal forms of social organisation. Pitt and colleagues $\left(2019^{*}\right)$ make this clear in their analysis of the situation of Sally, whose experience is threaded through with elements of hegemonic masculinity. Sally's feminised farm role (in rearing young animals) is used to pressure her into continuing to work on the farm, post-separation, with her abuser making her "feel bad for not going to his job and not doing his calves [feeding]" (Pitt et al., 2019*, p. 34). This limited Sally's space for action on financial, emotional, and safety vectors, as she continued to return to the property to feed the calves. Sally's abuser was able to garner more economic, practical, emotional, and social power through ongoing employment, remaining at home on the farm and maintaining positive relationships with her family throughout, particularly through masculinised rural pursuits, such as recreational fishing. In this way, notions of rural masculinity and concomitant feminine roles may serve to reduce women's space for action.

Contexts in which home and work are the same location, or, women work alongside their abusers, posed particular challenges to women's space for action. A participant in Ragusa's study $\left(2013^{*}\right)$ recounts her abuse while working in a motel, with her abuser monitoring her movements and accusing her of having sexual relationships with customers. Aside from the opportunities for surveillance, control, and abuse engendered by working alongside her abuser, elements of the rural landscape further compounded this woman's lack of space for action. She explains how they "had to go $70 \mathrm{~km}$ to the bank", indicating the isolation that can further complicate access to services (Ragusa, 2013*, p. 700). Coupled with the fact that work and home were the same place for this woman, and her space for action became extremely limited. This complex intertwining of the public and private spheres also resonated throughout examples of farming families in the data set, explored further below.

Farming repeatedly emerged as a rural-specific employment situation that limited women's space for action. For example, women who sought legal action (typically in the form of a restraining order) to address their partner's violence often found themselves in a double bind. In some jurisdictions, such as Victoria, Australia, where George and Harris $\left(2014^{*}\right)$ conducted their research, being the subject of a domestic violence restraining order prohibits that person from holding a firearms licence. Men who require a firearms licence for work - including farmers, but also men who work in the security industry - face significant employment ramifications should they lose their gun licence, with flow-on financial effects for their children. This places women in a difficult position regarding what, if any, legal action to take, and can become particularly problematic in a male breadwinner culture where women may be reliant on their abuser's income for their own or their children's survival.

Social norms and farm life were frequently shown to combine to restrict women's space for action. In particular, it emerged that farming systems and seasonal work often enabled financial abuse. Tina, in George and Harris' study, explained the ways in which her abuser justified his actions through the lens of 'tradition'; he was "taking care" of her in an "old fashioned" way (George \& Harris, 2014*, p. 48). This justification of being "old fashioned" was used to excuse maintaining Tina's social isolation and limiting her financial autonomy. In return for being "tak[en] care" of, she was expected to fulfil a domestic role and stay out of the business side of farming. Complications related to farming were frequently identified as 
restricting women's space for action. Women often do not receive a wage for farm work and cannot save money, thereby significantly limiting their financial independence - an issue that even more severely reduces the space for action of older women, who may have fewer opportunities to rebuild a future outside of relationships where the perpetrator is abusive (e.g. Hornosty \& Doherty, 2002*; Khan, 2015*). Alongside economic impacts, farm work collapses the boundaries between home and work, is often deeply emotional, and is bound up with children's financial or employment futures (Hornosty \& Doherty, 2002*; Loxton et al., 2003*; Pitt et al., 2019*). This can make family farms targets for emotional abuse and controlling behaviours; exiting an abusive relationship may mean the end of the farm, jeopardising children's futures. Being a farmer or part of a farming family can therefore severely limit women's space for action.

Seasonal work that is common in land-based occupations also emerged as a complicating factor for victim-survivors. In seasonal occupations, violence was often seen as linked to cycles of harvest, or times of stress related to the variability of work (e.g. Hornosty \& Doherty, 2002*; Mkandawire-Valhmu et al., 2019*). Women's space for action may be reduced in times where seasonal work is sparse, placing further financial pressure on families, or alternatively in times of increasing seasonal workloads, such as during harvest or when animals required intensive labour (e.g. Mkandawire-Valhmu et al., 2019*; Pitt et al., $\left.2019^{*}\right)$. At these times, women may put aside their own safety out of dedication to their animals, or for financial reasons, even though these high-stress times might also entail an escalation in violence (e.g. Hornosty \& Doherty, 2002*; Mkandawire-Valhmu et al., 2019*; Pitt et al., 2019*). In this way, the ebbs and flows of seasonal work appear to impact women's space for action through limiting their financial options or requiring them to make difficult choices to prioritise considerations such as animal welfare over their own safety.

Difficulties also emerged in the relationship between mothering and women's space for action. In Neilsen and Renou's study (2015), Kirsty's experience exemplifies how various rural factors combine to create barriers to help-seeking and inhibit her ability to parent. After her partner abducted their child at handover, Kirsty explains how she went to a rural police station, in tears, only to find it unattended, meaning she had to use "an intercom to a regional twenty four hour police station" (Neilson \& Renou, 2015*, p. 56). To her, the police "weren't all that fussed, said, "well we'll get in touch with him",, with it eventually taking "thirty six hours to get [her] daughter back" (Neilson \& Renou, 2015*, p. 56). Police cited a lack of resources as the reason they may not be able to remove Kirsty's daughter from her father, despite Kirsty's fears for her child's safety. This vignette demonstrates how the realities and social norms of rural life combine to inhibit space for action. Lack of resourcing, in this case an unattended police station, combined with the normalisation of violence, demonstrated via Kirsty's assertion that police "weren't all that fussed" about the abduction, limited Kirsty's ability to both seek assistance and protect her daughter. Challenges of distance, services, and social isolation often impacted on rural women's ability to care for and protect their children.

The social organisation of rural communities further restricted women's space for action in relation to mothering. As touched on above, previous research identifies challenges in small communities related to the social status of the abuser (DeKeseredy, 2015; Websdale, 1998; Wendt, 2009*). A participant in Wendt and Hornosty's (2010*) study articulates these challenges. After her children tried to tell people about the abuse perpetrated by their father, her daughter recounted that she does not "bother anymore because they don't want to know"; she had become accustomed to receiving responses such as "oh well your father tries to do the right thing" (p. 58). At the same time, women in rural locations may also have a greater 
The impact of rurality on women's 'space for action' in domestic violence: Findings from a meta-synthesis - Farhall, Harris and Woodlock

fear of being painted as a 'bad mother'. Opportunities for community surveillance are heightened, with women in the studies analysed expressing concern they might lose their children or be judged unfit mothers if they sought help or left their abusers (e.g. Burnett et al., 2015*; George \& Harris, 2014*; Hornosty \& Doherty, 2002*). Small, tight-knit communities, mean that space for action is significantly reduced.

Consideration of children's needs, interestingly, could either open up or close down women's space for action. Abuse of children, or seeing the impacts of abuse on children, was often identified as a catalyst to women exiting an abusive relationship. Yet, mothering responsibilities and dedication to one's children could also provide a reason to endure violence, or make compromises, for example through visitation arrangements with the perpetrator (e.g. Burnett et al., 2015*; Burton et al., 2016*; George \& Harris, 2014*; Maselesele et al., 2009*; Neilson \& Renou, 2015*). In a rural context, this may mean women decide not to relocate to a location further away from the perpetrator, or where they have greater anonymity, to ensure shared parenting. In this way, children represented a significant opportunity for abusers to limit women's space for action. This fact was compounded by the systemic, material, and social challenges of rural life.

The role of children as both a catalyst for action and a reason to endure or compromise resonates with findings from Sharp-Jeffs et al. (2017). They found that, while children could be used to control women, victim-survivors often had greater space for action in the domain of parenting. The scholars hypothesised this might be related to prioritising children's needs, or abusers viewing parenting as a woman's role. Evidence in the data suggests these theories have merit. However, in rural contexts, the extent to which children/childcare can be used to immobilise or keep women close, ultimately limiting their space for action, should not be underestimated.

\section{Conclusion}

Our findings reveal how women's space for action in rural communities can be foreclosed in rurally-specific ways. The geographical landscapes that define rural life can be employed by perpetrators as part of their tactics to constrain women's space for action, severely limiting their freedom, their opportunities to seek help and to protect themselves, and their avenues to leave perpetrators. Opportunities for surveillance and physical isolation in rural areas, exacerbated by the denial of access to, or exploitation of, technology, worked not only to constrain women's material choices but also to limit their psychological space for action, by constructing a world in which all exits out of the violence were barred.

In conjunction with the ways in which these material realities of rurality contributed to a reduction in women's ability to act, the social structures and norms of tight-knit rural communities further compounded these challenges. In conducting our meta-synthesis, it was striking how rural community values frequently produced shame and anxiety for victimsurvivors but yielded support and denial of culpability for abusers. Notably, the ways in which the data from small communities perpetuated male peer support theory, upholding narratives that 'good men don't abuse', severely reduced women's space for action, as they often felt that if they pursued either official or informal support, they would not be heard. And this was the reality for many women who were denied support by services, friends and family. Other challenges that are known to be more acute in rural communities, including barriers to service provision, access to appropriate alternative accommodation and confidence in the expertise and independence of formal responses (including whether external experts 
were well versed in the specificities of rural life), were also shown to limit women's ability and confidence in acting in their own defence or seeking to separate from the perpetrator. These obstacles to women taking steps towards freedom were often further complicated by perpetrator threats, or other forms of fear, that were generated or compounded by the rural location. At times, women felt that threats carried more weight due to the community policing (often by abuser's networks) made possible in small towns, or the geographical isolation that might stymie any escape.

Lastly, we found that the realities of rural life could be used to inhibit women's space for action in central areas of their lives, such as finance, work, and mothering. The gendered social norms and forms of organisation that are often prevalent in rural communities can render the difficult choices women often have to make between financial security and freedom from violence more acute. This was particularly visible in the case of farming families and family businesses; situations which further minimised women's space for action by blurring the lines between work and home. When these two are one and the same, the opportunities to escape violence are sharply reduced, while those for surveillance and control are heightened. Rural conditions also significantly impacted on women's space for action in the domain of parenting, with the normalisation of violence in rural areas combining with a lack of resourcing to inhibit women's ability to care for and keep their children safe. Interestingly, while children could often be a driver to leave an abusive partner, they could also provide reasons to endure violence or limit escape, particularly where post-separation co-parenting restricted women's ability to move away from the local community.

In all, a qualitative meta-synthesis of in-depth studies examining the experiences of rural victim-survivors of domestic violence shows that the spatiality, resourcing, and social conditions associated with the geographical rural location can impact on women's space for action in specific ways. Better understanding how these factors constrain women's space for action in rural communities can help us support women to take steps away from violence and towards freedom.

\section{Endnote}

${ }^{1}$ References with an asterisk indicate those articles/reports that were included in the final data set for this meta-synthesis. A full list of articles is available on request. 
The impact of rurality on women's 'space for action' in domestic violence: Findings from a meta-synthesis - Farhall, Harris and Woodlock

\section{References}

Bancroft, L. (2003). Why does he do that? Inside the minds of angry and controlling men. Penguin.

Bosch, K., \& Bergen, M. B. (2006). The influence of supportive and nonsupportive persons in helping rural women in abusive partner relationships become free from abuse. Journal of Family Violence, 21(5), 311-320. https://doi.org/10.1007/s10896-0069027-1

Braun, V., \& Clarke, V. (2006). Using thematic analysis in psychology. Qualitative Research in Psychology, 3(2), 77-101. https://doi.org/10.1191/1478088706qp063oa

Brownridge, D.A. (2009). Violence against women: Vulnerable populations. Routledge. https://doi.org/10.4324/9780203877432

Burnett, C., Schminkey, D., Milburn, J., Kastello, J., Bullock, L., Campbell, J., \& Sharps, P. (2015). Negotiating peril: The lived experience of rural, low-income women exposed to IPV during pregnancy and postpartum. Violence Against Women, 22(8), 943-965. https://doi.org/10.1177/1077801215614972

Burton, C. W., Halpern-Felsher, B., Rehm, R. S., Rankin, S. H., \& Humphreys, J. C. (2016). Depression and self-rated health among rural women who experienced adolescent dating abuse: A mixed methods study. Journal of Interpersonal Violence, 31(5), 920941. https://doi.org/10.1177/0886260514556766

Carrington, K., Hogg, R., Scott, J., Sozzo, M., \& Walters, R. (2019). Southern criminology. Routledge.

Davhana-Maselesele, M., Myburgh, C., \& Poggenpoel, M. (2009). Lived experiences of women victims of domestic violence in rural areas of Vhembe district: Limpopo province. Gender and behaviour, 7(2), 2517-2540.

https://doi.org/10.4314/gab.v7i2.48706

DeKeseredy, W.S. (1990). Male peer support and woman abuse: The current state of knowledge. Sociological Focus, 23, 129-139. https://doi.org/10.1080/00380237.1992.10570559

DeKeseredy, W. S. (2015). New directions in feminist understandings of rural crime. Journal of Rural Studies, 39, 180-187. https://doi.org/10.1016/j.jrurstud.2014.11.002

DeKeseredy, W. S., Dragiewicz, M., \& Schwartz, M. D. (2017). Abusive endings: Separation and divorce violence against women. University of California Press https://doi.org/10.1525/california/9780520285743.003.0001

DeKeseredy, W. S., \& Hall-Sanchez, A. (2017). Adult Pornography and Violence Against Women in the Heartland: Results from a rural southeast Ohio study. Violence Against Women, 23(7), 830-849. https://doi.org/10.1177/1077801216648795 
DeKeseredy, W. S., \& Schwartz, M. D. (2009). Dangerous Exits: Escaping Abusive Relationships in Rural America. New Brunswick, NJ: Rutgers University

Doherty, D. \& Hornosty, J. (2008). Exploring the links: Firearms, family violence and animal abuse in rural communities. Canada Firearms Centre Royal Canadian Mounted Police Public Safety Canada.

Gallup-Black, A. (2005). Twenty years of rural and urban trends in family and intimate partner homicide: Does place matter? Homicide Studies, 9, 149-73. https://doi.org/10.1177/1088767904274158

George, A., \& Harris, B. (2014). Landscapes of violence: Women surviving family violence in regional and rural victoria. Deakin University.

Harris, B., \& Woodlock, D. (2019). Digital coercive control: Insights from two landmark domestic violence studies. British Journal of Criminology, 59, 530-550. https://doi.org/10.1093/bjc/azy052

Hornosty, J., \& Doherty, D. (2002). Responding to wife abuse in farm and rural communities: Searching for solutions that work. Paper presented at The rural Canada: Moving forward or left behind? A national conference, Regina, Canada.

Jovanovski, N., \& Cook, K. (2019). The vulnerable-empowered mother of academic food discourses: a qualitative meta-synthesis of studies of low-income mothers and food provisioning. Health Sociology Review, 28(2), 107-125. https://doi.org/10.1080/14461242.2019.1578984

Kelly, L. (2003). The wrong debate: reflections on why force is not the key issue with respect to trafficking in women for sexual exploitation. Feminist Review, 73, 139-144. https://doi.org/10.1057/palgrave.fr.9400086

Khan, A. R. (2015). Women's coping strategies and help-seeking practices: Some observations on domestic violence in rural Bangladesh. Asian Journal of Women's Studies, 21(3), 252-272. https://doi.org/10.1080/12259276.2015.1072941

Lichtenstein, B., \& Johnson, I. M. (2009). Older African American women and barriers to reporting domestic violence to law enforcement in the rural deep south. Women \& Criminal Justice, 19(4), 286-305. https://doi.org/10.1080/08974450903224329

Logan, T. K., Shannon, L., Cole, J., \& Swanberg, J. E. (2007). Partner stalking and implications for women's employment. Journal of Interpersonal Violence, 22(3), 268291. https://doi.org/10.1177/0886260506295380

Logan, T. K., Walker, R., Cole, J., Ratliff, S., \& Leukefeld, C. (2003). Qualitative differences among rural and urban intimate violence victimization experiences and consequences: A pilot study. Journal of Family Violence, 18, 83-92. https://doi.org/10.1023/A:1022837114205

Loxton, D., Hussain, R., \& Schofield, M. (2003). Women's experiences of domestic abuse in rural and remote Australia. Paper presented at the 7th National Rural Health Conference, Hobart, Australia. 
The impact of rurality on women's 'space for action' in domestic violence: Findings from a meta-synthesis - Farhall, Harris and Woodlock

Lundgren, E. (1998). The hand that strikes and comforts: Gender construction and the tension between body and symbol. In R.E. Dobash and R.P. Dobash (Eds.), Rethinking violence against women (pp. 169-196). Sage. https://doi.org/10.4135/9781452243306.n7

Mackenzie, C., \& MacKay, T. (2019). 'I just wanted to keep my boyfriend happy': Young country women's perceptions of intimate partner violence. The University of South Australia.

Mkandawire-Valhmu, L., Bauer, W. S., Stevens, P. E., Galvao, L. W., Grande, K. M., Yerges, A., Emer, L., Mwenyekonde, T., \& Weinhardt, L. (2019). Rural Malawian women's resistance to systematic oppression, violence, and abuse by their husbands. Journal of Interpersonal Violence, 35(1-2), 268-293. https://doi.org/10.1177/0886260516682518

Moosavi, L. (2019). A friendly critique of 'Asian Criminology' and 'Southern Criminology'. British Journal of Criminology, 59, 257-275. https://doi.org/10.1093/bjc/azy045

Murray, L., Warr, D., Chen, J., Block, K., Murdolo, A., Quiazon, R., Davis, E., \& Vaughan, C. (2019). Between 'here' and 'there': family violence against immigrant and refugee women in urban and rural Southern Australia. Gender, Place \& Culture, 26(1), 91110. https://doi.org/10.1080/0966369X.2018.1553862

National Rural Crime Network. (2019). Captive and controlled: Domestic abuse in rural areas. National Rural Crime Network.

Neilson, C., \& Renou, B. (2015). Will somebody listen to me? Insight, actions and hope for women experiencing family violence in regional Victoria. Loddon Campaspe Community Legal Centre.

Noble-Carr, D., Moore, T., \& McArthur, M. (2019). Children's experiences and needs in relation to domestic and family violence: Findings from a meta-synthesis. Child \& Family Social Work, 25(1), 182-191. https://doi.org/10.1111/cfs.12645

Pain, R. (2015). Intimate war. Political Geography, 44, 64-73. https://doi.org/10.1016/j.polgeo.2014.09.011

Pfitzner, N., Fitz-Gibbon, K., \& True, J. (2020). Responding to the 'shadow pandemic': practitioner views on the nature of and responses to violence against women in Victoria, Australia during the COVID-19 restrictions. Monash University.

Pitt, L., Maidment, J., \& Crichton-Hill, Y. (2019). Women's experiences of intimate partner violence in rural Taranaki, Aotearoa New Zealand. Aotearoa New Zealand Social Work, 31(1), 31-41. https://doi.org/10.11157/anzswj-vol31iss1id533

Ragusa, A. T. (2013). Rural Australian women's legal help seeking for intimate partner violence: Women intimate partner violence victim survivors' perceptions of criminal justice support services. Journal of Interpersonal Violence, 28(4), 685-717. https://doi.org/10.1177/0886260512455864 
Ragusa, A. T. (2017). Rurality's influence on women's intimate partner violence experiences and support needed for escape and healing in Australia. Journal of Social Service Research, 43(2), 270-295. https://doi.org/10.1080/01488376.2016.1248267

Saini, M., \& Shlonsky, A. (2012). Systematic synthesis of qualitative research. Oxford University Press. https://doi.org/10.1093/acprof:oso/9780195387216.001.0001

Sandberg, L. (2013). Backward, dumb, and violent hillbillies? Rural geographies and intersectional studies on intimate partner violence. Affilia, 28, 350-65. https://doi.org/10.1177/0886109913504153

Sandelowski, M., Barroso, M. (2007). Handbook for synthesizing qualitative research. Springer.

Sharp-Jeffs, N., Kelly, L., \& Klein, R. (2017). Long journeys toward freedom: The relationship between coercive control and space for action-Measurement and emerging evidence. Violence Against Women, 24(2), 163-185. https://doi.org/10.1177/1077801216686199

Valentine, G. (1989). The geography of women's fear. Area, 385-390.

Veltri, G. A., Lim, J., \& Miller, R. (2014). More than meets the eye: The contribution of qualitative research to evidence-based policy-making. Innovation: The European Journal of Social Science Research, 27(1), 1-4. https://doi.org/10.1080/13511610.2013.806211

Websdale, N. (1998). Rural woman battering and the justice system: an ethnography. Sage.

Websdale, N., \& Johnson, B. (1998). An ethnostatistical comparison of the forms and levels of woman battering in urban and rural areas of Kentucky. Criminal Justice Review, 23, 161-96. https://doi.org/10.1177/073401689802300203

Wendt, S. (2009). Constructions of local culture and impacts on domestic violence in an Australian rural community. Journal of Rural Studies, 25, 175-184. https://doi.org/10.1016/j.jrurstud.2008.11.001

Wendt, S., Chung, D., Elder, A., Hendrick, A., \& Hartwig, A. (2017). Seeking help for domestic and family violence: Exploring regional, rural, and remote women's coping experiences. Final report. ANROWS. https://d2rn9gno7zhxqg.cloudfront.net/wpcontent/uploads/2019/02/19025231/RP.14.04_RWR_Horizons-FINAL-1709.pdf

Wendt, S., \& Hornosty, J. (2010). Understanding contexts of family violence in rural, farming communities: Implications for rural women's health. Rural Society, 20(1), 5163. https://doi.org/10.5172/rsj.20.1.51

World Health Organization. (2017). Violence against women fact sheet. Retrieved from http://www.who.int/news-room/fact-sheets/detail/violence-against-women. 